\title{
Efficacy and Safety of Oral Budesonide in Patients with Active Crohn's Disease in Japan: A Multicenter, Double-Blind, Randomized, Parallel-Group Phase 3 Study
}

\author{
Tadashi Yokoyama $^{a}$ Akihiko Ohta $^{\mathrm{b}}$ Satoshi Motoya ${ }^{c}$ Masakazu Takazoe $^{\mathrm{d}}$ \\ Toshitaka Yajima ${ }^{e}$ Masataka Date ${ }^{e}$ Masahiro Nii ${ }^{e}$ Péter Nagy $^{\text {h }}$ Yasuo Suzuki $^{f}$ \\ Toshifumi Hibi ${ }^{9}$ \\ aYokoyama Hospital for Gastroenterological Diseases, Nagoya, 'bIEDA Hospital, Aichi, ' Sapporo-Kosei General \\ Hospital, Sapporo, ${ }^{\mathrm{d}}$ Tokyo Yamate Medical Center, Tokyo, e AstraZeneca K.K., Osaka, ${ }^{\mathrm{f}}$ Toho University Sakura

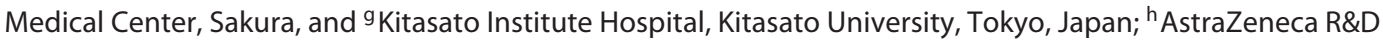 \\ Gothenburg, Mölndal, Sweden
}

\section{Keywords}

Budesonide · Crohn's disease · Efficacy · Japan · Mesalazine

\begin{abstract}
Background: US and European guidelines recommend budesonide for the treatment of mild-to-moderate active ileocolic Crohn's disease (CD). However, budesonide has not been approved, and mesalazine is widely used as first-line treatment in Japan. The objective of this study was to evaluate the efficacy and safety of budesonide in patients with mild-to-moderate active CD in Japan. Methods: In this phase 3 noninferiority study (NCT01514240), 112 patients with a baseline Crohn's Disease Activity Index (CDAl) score of 180 400 were randomized to budesonide or mesalazine for 8 weeks. Assessments included remission rate (CDAl score $\leq 150$ ) at weeks 2,4 , and 8 , change in CDAl score, health-related quality of life (measured using the Inflammatory Bowel Disease Questionnaire [IBDQ]), and tolerability. Results: The remission rate at week 8 was numerically higher in the
\end{abstract}

\begin{tabular}{ll}
\hline KARGER & $\begin{array}{l}\text { ( } 2017 \text { The Author(s) } \\
\text { Published by S. Karger AG, Basel }\end{array}$ \\
$\begin{array}{l}\text { E-Mail karger@karger.com } \\
\text { www.karger.com/iid }\end{array}$ & $\begin{array}{l}\text { This article is licensed under the Creative Commons Attribution- } \\
\text { NonCommercial-NoDerivatives 4.0 International License (CC BY- } \\
\text { NC-ND) (http://www.karger.com/Services/OpenAccessLicense) } \\
\text { Usage and distribution for commercial purposes as well as any dis- } \\
\text { tribution of modified material requires written permission. }\end{array}$
\end{tabular}

budesonide group (30.4\%) than in the mesalazine group (25.0\%), and the noninferiority of budesonide to mesalazine was shown. The mean total CDAI score decreased to a greater extent with budesonide than with mesalazine. Mean IBDQ scores improved from baseline to weeks 2, 4, 8, and 10 in both groups; improvements were numerically higher with budesonide than with mesalazine. No safety concerns were found. Conclusion: Budesonide is comparably effective to mesalazine in the treatment of Japanese patients with mildto-moderate active $\mathrm{CD}$.

(C) 2017 The Author(s)

Published by S. Karger AG, Basel tribution of modified material requires written permission. 


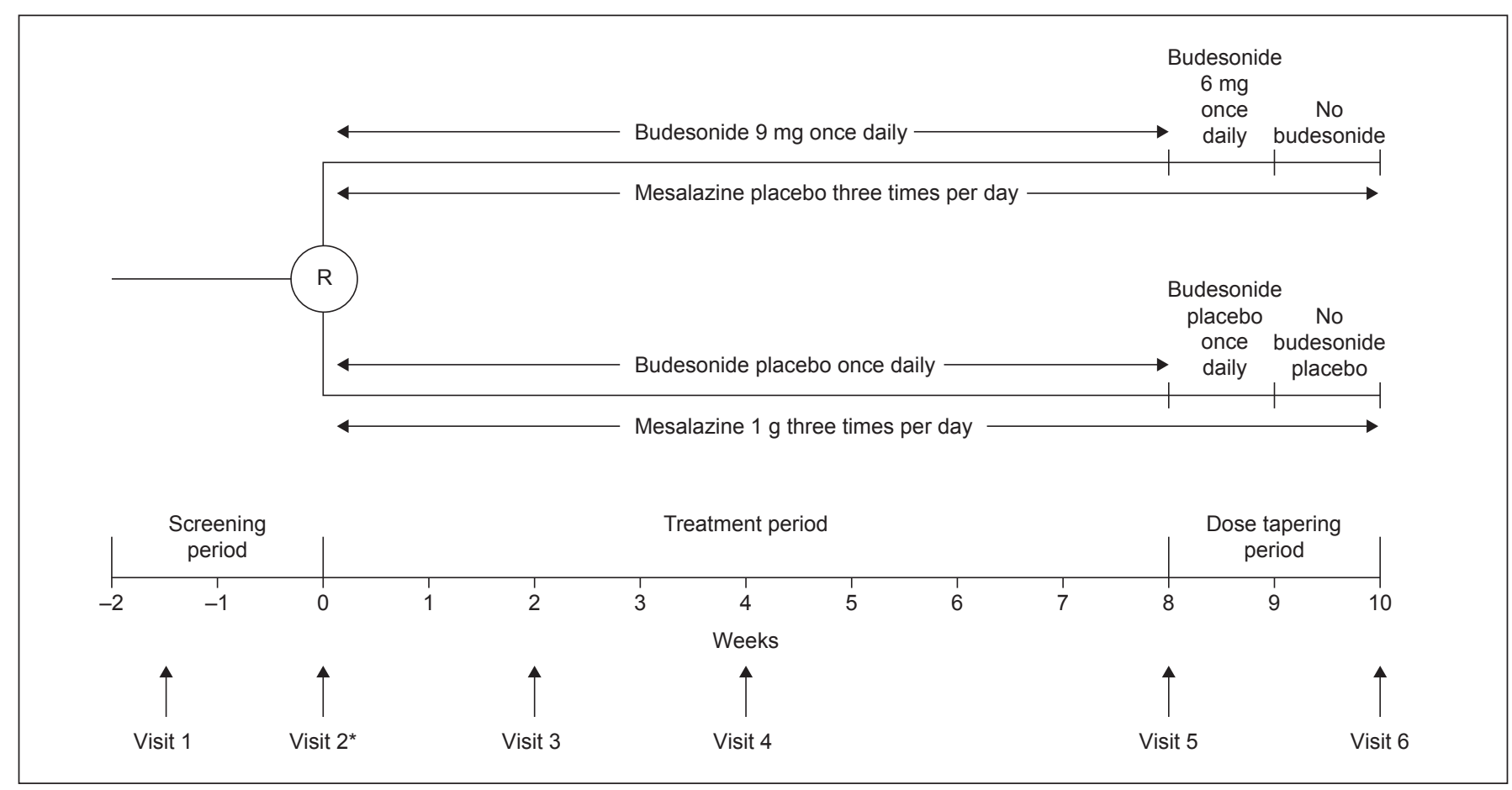

Fig. 1. Flowchart of the study design. * To be eligible for randomization, patients must have had a Crohn's Disease Activity Index score between 180 and 400 for a 1-week period during the screening period. R, randomization.

mation from 2013 showed that approximately 40,000 patients in Japan received registered treatment for CD in that year [2]. The treatment guidelines for CD in Japan describe 5-aminosalicylic acid (mesalazine) as a common first-line treatment for mild-to-moderate disease [3].

US and European guidelines recommend the glucocorticoid budesonide as a treatment for mild-to-moderate active ileocolic $\mathrm{CD}$ because it results in a higher rate of remission induction than mesalazine $[4,5]$. However, budesonide had not been approved in Japan at the time the Japanese guidelines were published (in 2013) [3].

Budesonide is approved for use in CD in about 40 countries worldwide. In Western populations, it has been shown to be as effective as prednisolone in the treatment of mild-to-moderate CD [6, 7], and to be more effective than mesalazine in inducing remission [8]. The efficacy of budesonide in Japanese patients with mild-to-moderate active $\mathrm{CD}$ was investigated in a phase 2 study; the proportion of individuals achieving remission after 8 weeks was higher in the budesonide groups than in the placebo group ( 23 and $28 \%$ with budesonide $9 \mathrm{mg}$ and $15 \mathrm{mg}$ once daily [q.d.], respectively, vs. $12 \%$ with placebo), although the differences between the two budesonide dose groups or between the budesonide and placebo groups were not statistically significant [9]. In Japan, budesonide was approved for induction of remission in patients with mildto-moderate active CD in September 2016.

The purpose of this phase 3 study was to evaluate the clinical efficacy, safety, and tolerability of budesonide $9 \mathrm{mg}$ q.d. compared with mesalazine $1 \mathrm{~g}$ three times daily (t.i.d.) in patients with mild-to-moderate active CD in Japan by assessing remission of CD after 8 weeks of treatment. It was hypothesized that the remission rate with budesonide would be noninferior to that with mesalazine.

\section{Methods}

\section{Study Design}

This was a phase 3, randomized, double-blind, parallel-group, multicenter trial (NCT01514240) conducted at 31 centers across Japan between February 2012 and September 2014. A flowchart of the study design is shown in Figure 1.

The trial comprised a 2-week screening period, an 8-week treatment period, and a 2 -week dose tapering period. Eligible patients were first stratified according to whether or not they were receiving concomitant treatment with azathioprine/6-mercaptopurine, and then randomized in a 1:1 ratio to receive either oral 
Table 1. Baseline demographics, disease characteristics, and previous disease-related medication use (full analysis set, $n=112$ )

\begin{tabular}{|c|c|c|}
\hline Characteristic & $\begin{array}{l}\text { Budesonide } \\
(n=56)\end{array}$ & $\begin{array}{l}\text { Mesalazine } \\
(n=56)\end{array}$ \\
\hline Mean age, years & $38(13)$ & $36(11)$ \\
\hline Male & $37(66 \%)$ & $43(77 \%)$ \\
\hline \multicolumn{3}{|l|}{ Ethnicity } \\
\hline Japanese & $56(100 \%)$ & $53(95 \%)$ \\
\hline Non-Japanese Asian & $0(0 \%)$ & $3(5 \%)$ \\
\hline Mean BMI & $21.0(3.2)$ & $21.0(3.5)$ \\
\hline Mean disease duration, years & $8.6(8.9)$ & $7.8(7.3)$ \\
\hline \multicolumn{3}{|l|}{ CDAI score } \\
\hline Mean & $255(55)$ & $263(69)$ \\
\hline$<300$ & $45(80 \%)$ & $42(75 \%)$ \\
\hline$\geq 300$ & $11(20 \%)$ & $14(25 \%)$ \\
\hline Mean IBDQ total score & $155(28)$ & $154(28)$ \\
\hline \multicolumn{3}{|c|}{ Concomitant use of nutritional therapy and/or immune suppression } \\
\hline Nutritional therapy only & $20(36 \%)$ & $16(29 \%)$ \\
\hline Immune suppression only & $8(14 \%)$ & $3(5 \%)$ \\
\hline Nutritional therapy and immune suppression & $6(11 \%)$ & $11(20 \%)$ \\
\hline \multicolumn{3}{|l|}{ Affected area } \\
\hline Ascending colon only & $6(11 \%)$ & $3(5 \%)$ \\
\hline Ileum only & $22(39 \%)$ & $32(57 \%)$ \\
\hline Ileocecal region and ascending colon & $28(50 \%)$ & $21(38 \%)$ \\
\hline \multicolumn{3}{|c|}{ Concomitant use of azathioprine or 6-mercaptopurine at study entry } \\
\hline Azathioprine & $12(21 \%)$ & $12(21 \%)$ \\
\hline Mean dose, mg & $54.2(20.0)$ & $52.1(23.8)$ \\
\hline 6-Mercaptopurine & $2(4 \%)$ & $2(4 \%)$ \\
\hline Mean dose, mg & 10 & 19 \\
\hline \multicolumn{3}{|l|}{ Previous disease-related medication use } \\
\hline Mesalazine & $48(86 \%)$ & $46(82 \%)$ \\
\hline Adalimumab & $4(7 \%)$ & $3(5 \%)$ \\
\hline Infliximab & $1(2 \%)$ & $6(11 \%)$ \\
\hline
\end{tabular}

Figures in parentheses represent percentages or standard deviations. BMI, body mass index; CDAI, Crohn's Disease Activity Index; IBDQ, Inflammatory Bowel Disease Questionnaire.

budesonide $9 \mathrm{mg}$ q.d. before breakfast with placebo for mesalazine t.i.d. or oral mesalazine $1 \mathrm{~g}$ t.i.d. after meals with placebo for budesonide q.d. for the 8-week treatment phase. The randomization scheme was generated by a third party (a registration center), takingintoaccounttheinformation on concomitantazathioprine/6mercaptopurine use. The budesonide $9 \mathrm{mg}$ dose was selected based on results from the dose-finding study [10] and the phase 2 trial in Japanese patients [9]. Budesonide capsules and matching placebo were obtained from AstraZeneca, Sweden, and mesalazine timerelease tablets and matching placebo were obtained from KYORIN Pharmaceutical Co. Ltd., Japan. In keeping with the double-blind, double-dummy study design, patients in the budesonide group received a budesonide capsule q.d. before breakfast and a mesalazine placebo tablet t.i.d. after each meal, and patients in the mesalazine group received a budesonide placebo capsule q.d. before breakfast and a mesalazine tablet t.i.d. after each meal.

During the dose tapering period, patients in the budesonide group received budesonide $6 \mathrm{mg}$ q.d. during week 9 and no budesonide treatment during week 10. Patients in the mesalazine group continued to receive mesalazine $1 \mathrm{~g}$ t.i.d. during weeks 9 and 10. Matching placebo was continued during the dose tapering period in both groups. Patients completed a diary card on $\geq 7$ consecutive days during the screening phase and daily during the treatment phase. Investigators used the diary cards to record the variables for calculating the Crohn's Disease Activity Index (CDAI) score. In addition, patients completed the validated Japanese version of the Inflammatory Bowel Disease Questionnaire (IBDQ) at weeks 0-10 (visits 2-6) [11, 12].

\section{Study Participants}

Patients aged $\geq 15$ years were eligible for inclusion in the study if they had a diagnosis of active CD verified by X-ray, endoscopy, or histology affecting the ileum, ileocecal region, and/or ascending colon. In addition, to be eligible for randomization, patients had to have had a CDAI score between 180 and 400 inclusive for a 1 -week period during the screening phase [13]. The presence of 
CD was confirmed in the time period before enrollment and active disease status in the screening phase via the CDAI. The lower age limit of 15 years was chosen to include adolescents in their late teens who are part of the age group in whom CD commonly first appears, and to reflect the need for therapy in these age groups, the medication use globally, and mesalazine use in Japan.

Patients receiving a partial, specialized "elemental diet" as nutritional treatment ( $\leq 1,200 \mathrm{kcal} /$ day) [14] were eligible for inclusion if their calorie intake had remained constant from 2 weeks before randomization; calorie intake had to remain constant until the end of the study or discontinuation. Patients receiving azathioprine $(\leq 2.0 \mathrm{mg} / \mathrm{kg} /$ day $)$ or 6 -mercaptopurine $(\leq 1.2 \mathrm{mg} / \mathrm{kg} /$ day $)$ were eligible for inclusion if their treatment dose had remained constant from 12 weeks before randomization; the dose had to remain constant until the end of the study or discontinuation.

The main exclusion criteria were: presence of an ileostomy, pouch, or colostomy; resection of the ileum totaling $\geq 100 \mathrm{~cm}$; previous total gastrectomy; active CD of the rectum or anus; systemic infection; history of gastrointestinal malignancy, high-grade dysplasia, or carcinoma; active peptic disease; and uncontrolled diabetes mellitus. Patients receiving infliximab during the 8 weeks before randomization, or glucocorticoids, adalimumab, antibiotics for $\mathrm{CD}$, or mesalazine ( $\geq 2,251 \mathrm{mg} /$ day) during $\geq 2$ weeks before randomization were also excluded, as were women who were pregnant, breastfeeding, or of childbearing age and not using medically accepted contraception. Mesalazine as concomitant medication was stopped the day before randomization.

\section{Efficacy Assessments}

The primary efficacy variable was the rate of remission at week 8 , defined as a CDAI score $\leq 150$. Secondary efficacy variables were remission rate at weeks 2 and 4, change in CDAI score, clinical improvement defined as remission (CDAI score $\leq 150$ ) or a decrease in CDAI score $\geq 100$ from week 0 (visit 2) after 2,4 , and 8 weeks of treatment, clinical improvement defined as remission (CDAI score $\leq 150$ ) or a decrease in CDAI score $\geq 70$ from week 0 (visit 2) after 2, 4, and 8 weeks of treatment, and change in diseasespecific health-related quality of life (assessed using the IBDQ).

\section{Safety Assessments}

The following safety variables were assessed: adverse events, laboratory variables (hematology, clinical chemistry including serum dehydroepiandrosterone sulfate [DHEA-S] and C-reactive protein [CRP] levels, and urinalysis), vital signs (pulse, blood pressure, and body temperature), and physical examination findings.

\section{Statistical Analyses}

The sample size was calculated to demonstrate noninferiority of budesonide to mesalazine with regard to the primary variable, the remission rate at week 8 , using a $10 \%$ noninferiority margin. The remission rate was expected to be $28 \%$ in the budesonide group and $15 \%$ in the mesalazine group, based on results from a phase 3 study [15] and the phase 2 trial in Japanese patients [9]. Evaluable data from 54 patients in each treatment group were required to provide $90 \%$ power to show the lower limit of the twosided $90 \%$ confidence interval (CI) for a between-group difference higher than $-10 \%$. The noninferiority design is a potential weakness of the study; however, this research, including the choice of study design, was undertaken in consultation with the Japanese regulatory agency (Pharmaceutical and Medical Devices Agency).

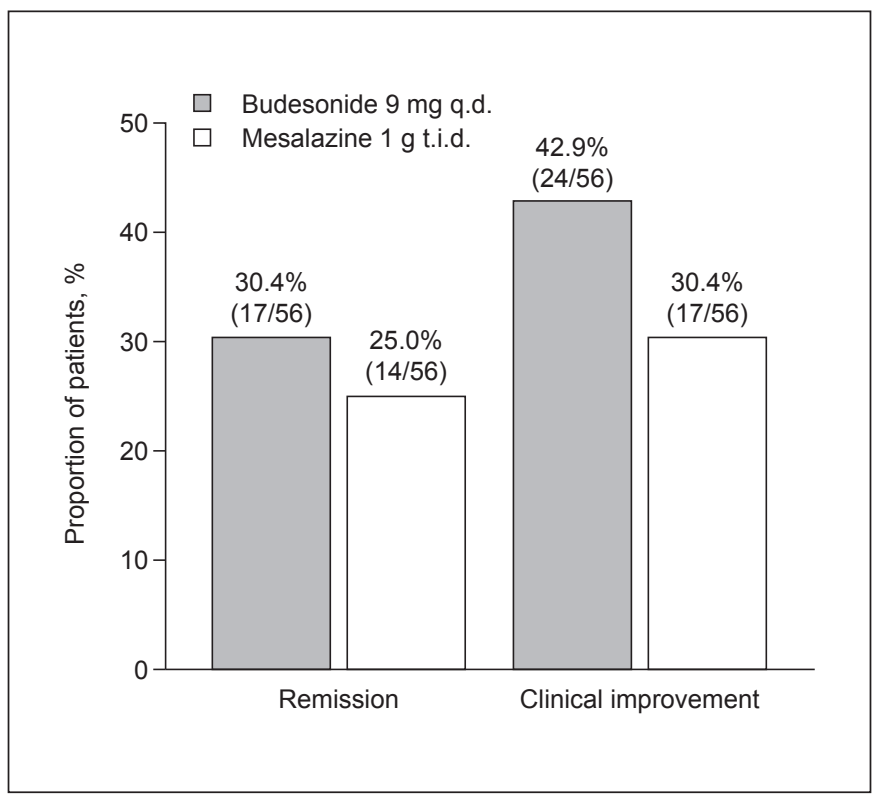

Fig. 2. Rates of remission (Crohn's Disease Activity Index [CDAI] score $\leq 150$ ) and clinical improvement (CDAI score $\leq 150$ or CDAI score decrease from baseline $\geq 100$ ) at week 8 of the treatment phase. q.d., once daily; t.i.d., three times daily.

Efficacy analyses were performed using the full analysis set. Differences in rates of remission and clinical improvement were analyzed along with their two-sided $90 \%$ CIs using the NewcombeWilson score method without continuity correction $[16,17]$. Remission rates between treatment groups were also compared using $\chi^{2}$ tests. Subgroup and secondary efficacy analyses were descriptive only.

\section{Results}

\section{Study Participants}

A total of 112 patients were included in the study. After stratification according to whether or not they were taking concomitant azathioprine or 6-mercaptopurine (yes: $n=28$ [25\%]; no: $n=84$ [75\%]), patients were randomized $1: 1$ to receive budesonide or mesalazine (online suppl. Fig. S1; see www.karger.com/doi/10.1159/000484047 for all online suppl. material). Twelve patients $(21 \%)$ in each treatment group were taking azathioprine, and 2 (4\%) in each group were taking 6-mercaptopurine.

The trial was completed by $89 \%$ of the patients treated with budesonide (50/56) and by $80 \%$ of those receiving mesalazine (45/56). Baseline demographics, disease characteristics, and previous disease-related medication use are listed in Table 1 for all randomized patients. 
Table 2. Remission rates at week 8 , overall and by subgroup (full analysis set, $n=112$ )

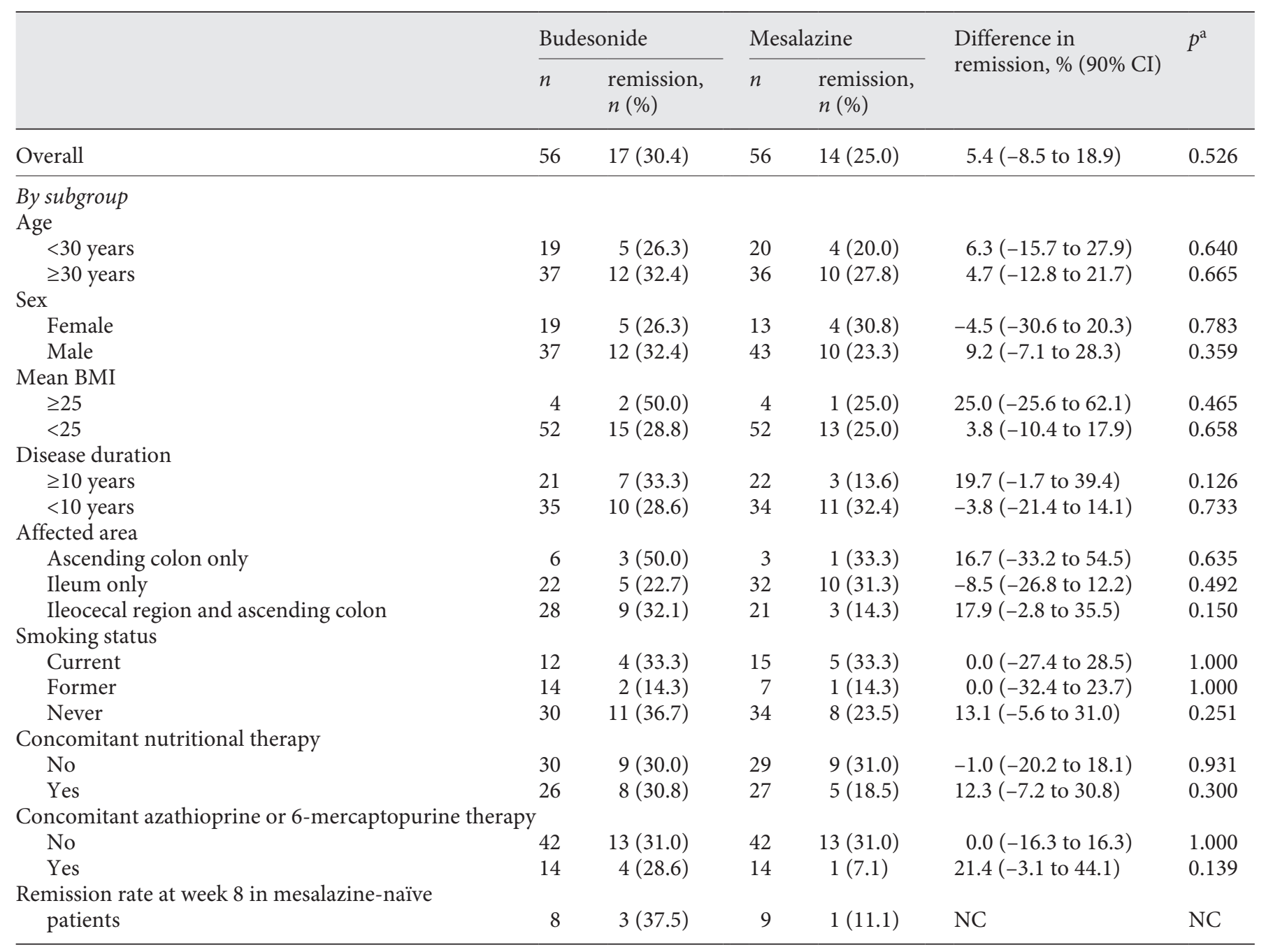

BMI, body mass index; CI, confidence interval; NC, not calculated. ${ }^{a}$ Calculated using the $\chi^{2}$ test.

\section{Efficacy Assessments}

Primary Assessments. The proportion of patients who achieved remission at week 8 was numerically higher in the budesonide group than in the mesalazine group $(30.4$ vs. $25.0 \%$; $p=0.526$; Fig. 2 ; Table 2). The between-group difference of $5.4 \%$ (90\% CI -8.5 to 18.9 ) indicated noninferiority of budesonide $9 \mathrm{mg}$ q.d. to mesalazine $1 \mathrm{~g}$ t.i.d. for clinical remission. Remission rates by subgroups, listed in Table 2, were generally in line with the main analysis.

Secondary Assessments. The proportion of patients who achieved remission was numerically higher in the budesonide group than in the mesalazine group at week 2 (12.5 and $10.7 \%$, respectively; $p=0.768)$ and at week 4
(21.4 and $12.5 \%$, respectively; $p=0.208$ ). While there was no statistically significant difference between the two groups, the decrease in mean total CDAI score from baseline was slightly greater in the budesonide group than in the mesalazine group at weeks 2,4 , and 8 (Fig. 3a). The cumulative remission rate increased over time in both treatment groups and was numerically higher in the budesonide group than in the mesalazine group. The proportion of patients with clinical improvement defined as a CDAI score $\leq 150$ or a CDAI score decrease from baseline $\geq 100$ was numerically higher in the budesonide group than in the mesalazine group at week 2 (25.0 vs. $17.9 \%)$, week 4 (33.9 vs. $19.6 \%$ ), and week 8 (42.9 vs. $30.4 \%$ ) (Fig. 2). The proportion of patients with clinical 


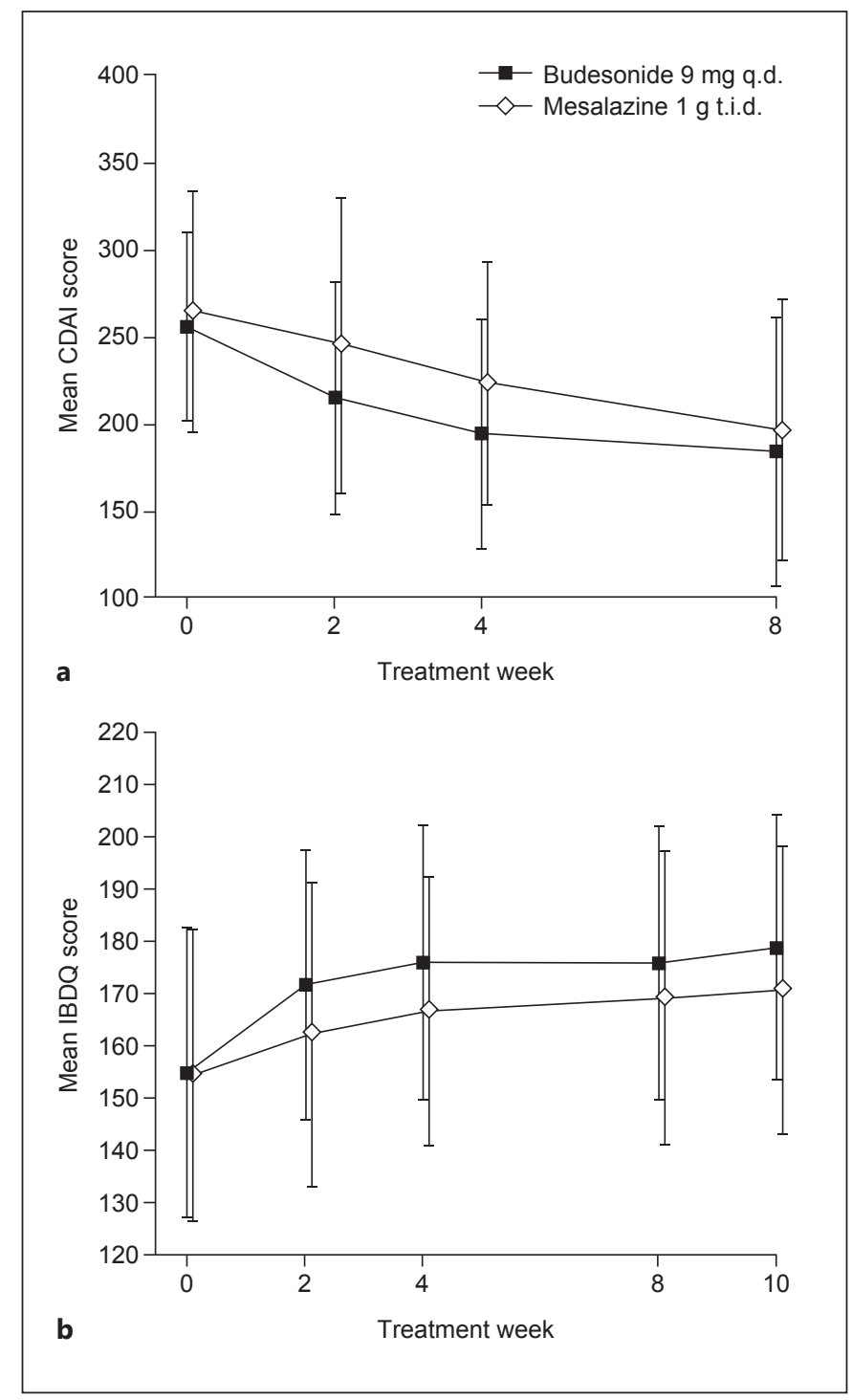

Fig. 3. Mean Crohn's Disease Activity Index (CDAI) score (a) and Inflammatory Bowel Disease Questionnaire (IBDQ) total score (b) at randomization (week 0 , baseline) and during the treatment phase (at weeks 2, 4, and 8) and during the second week of the dose-tapering phase (week 10) for IBDQ. Vertical bars indicate standard deviations. q.d., once daily; t.i.d., three times daily.

improvement defined as a CDAI score $\leq 150$ or a CDAI score decrease from baseline $\geq 70$ was also numerically higher in the budesonide group than in the mesalazine group at week 2 (33.9 vs. $19.6 \%$ ), week 4 (39.3 vs. $23.2 \%)$, and week 8 (48.2 vs. 32.1\%). Mean IBDQ scores improved from baseline to weeks $2,4,8$, and 10 in both treatment groups, with improvements being numerically higher in the budesonide group than in the mesalazine group (Fig. 3b).

Budesonide versus Mesalazine for Active Crohn's Disease

\section{Safety and Tolerability}

The mean duration of exposure was 61 days for budesonide and 62 days for mesalazine. Online supplementary Table S1 shows the number of patients reporting adverse events in any category and lists adverse events that occurred in $>5 \%$ of patients in a treatment group. No patients $(0 \%)$ in the budesonide group and $1(2 \%)$ in the mesalazine group experienced adverse events with severe intensity. Three patients (5\%) in the budesonide group and $1(2 \%)$ in the mesalazine group experienced $\geq 1$ serious adverse event. None of the serious adverse events were considered by the investigators to be related to the study drug. The number of patients discontinuing treatment because of adverse events was the same in the budesonide group $(n=4,7 \%)$ as in the mesalazine group $(n=4,7 \%)$. The number of possible glucocorticoid-related adverse events was small, with no important differences between the budesonide and mesalazine groups: 1 patient in the budesonide group experienced a possible glucocorticoid-related adverse event (dermatitis acneiform of mild intensity), which led to therapy discontinuation.

No safety concerns were raised in either of the treatment groups. There were no clinically significant differences in hematological values between the budesonide group and the mesalazine group. Mean values for CRP and DHEA-S were lower in the budesonide group than in the mesalazine group up to 8 weeks, and the values returned towards baseline after the dose tapering period in both groups. No clinically significant differences in clinical chemistry values were observed between the two treatment groups (online suppl. Table S2).

\section{Discussion}

This phase 3 study, conducted in patients with mildto-moderate active CD in Japan, met its primary objective of showing noninferiority of budesonide $9 \mathrm{mg}$ q.d. to mesalazine $1 \mathrm{~g}$ t.i.d. for remission at week 8 . The results for secondary variables were consistent with those for the primary variable in terms of demonstrating noninferiority of budesonide to mesalazine. The rates of improvement were numerically higher in the budesonide group than in the mesalazine group, an effect that could already be observed at weeks 2 and 4 . To our knowledge, this is the first study to compare budesonide with mesalazine in patients with $\mathrm{CD}$ in not only the Japanese but also in the non-Japanese Asian population $(n=3)$. The initial plan had been for the study to enroll only treatment-naïve pa- 
Table 3. Mean disease duration, budesonide formulation, allowed concomitant medications, and proportion of patients using azathioprine/6-mercaptopurine comedication in the current study and in Western population studies

\begin{tabular}{|c|c|c|c|c|}
\hline Reference & Mean disease duration, years & $\begin{array}{l}\text { Budesonide } \\
\text { formulation }\end{array}$ & $\begin{array}{l}\text { Allowed concomitant } \\
\text { study medications }\end{array}$ & $\begin{array}{l}\text { AZA/6-MP } \\
\text { comedication }\end{array}$ \\
\hline Current study & 8.6 & acid-stable & AZA, 6-MP & $25 \%$ \\
\hline Thomsen et al., 1998 [8] & $6.1^{\mathrm{a}}$ & $\mathrm{pH}$-dependent release & none reported & $\mathrm{N} / \mathrm{A}$ \\
\hline Campieri et al., 1997 [6] & 7.9 (q.d. group); 8.3 (b.i.d. group) & acid-stable & none reported & $\mathrm{N} / \mathrm{A}$ \\
\hline Greenberg et al., 1994 [10] & $5.9^{\mathrm{b}}$ & acid-stable & none reported & $\mathrm{N} / \mathrm{A}$ \\
\hline
\end{tabular}

6-MP, 6-mercaptopurine; AZA, azathioprine; b.i.d., twice a day; N/A, not applicable; q.d., once daily. ${ }^{\mathrm{a}}$ Median. ${ }^{\mathrm{b}}$ Budesonide 9 mg group.

tients with CD. However, this was changed such that those who had previously used disease-related medication could also be included so that the study design would better reflect real clinical settings.

Remission was assessed using the CDAI, which is recommended by the Japanese CD treatment guidelines for the objective evaluation of disease activity and severity [3]. The CDAI assesses symptom relief, which, although it does not always correlate with mucosal healing, might nevertheless be a preferred outcome from a patient perspective. Stratification of patients according to the use of concomitant immunomodulation therapy with azathioprine or 6-mercaptopurine ensured that there would be no differential effect of these agents on budesonide treatment compared with mesalazine treatment. Budesonide therapy had a good safety and tolerability profile in the present study. Although budesonide is a glucocorticoid, it has low systemic bioavailability and a significantly lower rate of glucocorticoid-related adverse events than prednisolone [18], a therapy that is recommended in Japan for patients with moderate-to-severe CD [3].

Together with control of disease activity, the Japanese treatment guidelines for CD list improvement in patients' quality of life as the main goal of therapy [3]. In the present study, disease-specific health-related quality of life, as measured using the IBDQ, improved in both treatment groups. However, improvements in score were numerically greater in the budesonide group than in the mesalazine group, mirroring the greater decrease in disease activity score in the budesonide group than in the mesalazine group. The present study included a 2 -week dose tapering period after the 8-week treatment period. Quality of life was evaluated using the IBDQ up to week 10, thereby providing new information about post-treatment effects that has not been reported in previous studies of budesonide and mesalazine.

The results of the present study are supported by those of a phase 2 study in Japanese patients with mild-to-moderate CD, which showed a remission rate at week 8 of $23 \%$ with budesonide $9 \mathrm{mg}$ q.d. (compared with $12 \%$ with placebo) [9]. The remission rates observed in the present study and in the phase 2 study in Japanese patients [9] are lower than those reported in Western populations [15]. This may be explained by differences in concomitant medication taken by the study populations or by their differing disease histories (Table 3). The mean disease duration in patients in the present study was longer than that in the study in Western populations ( 8.2 vs. 6.0 years) [15], and patients in the present study were thus more likely to have already tried different treatments and to be treatment resistant.

The present study is the first to compare budesonide and mesalazine for the treatment of patients with $\mathrm{CD}$ as an add-on to concomitant therapy and to report these data separately for subgroups with concomitant therapy versus those without, thereby providing important new information in this field of study. There were no statistically significant differences in remission rates between budesonide and mesalazine, regardless of the use of concomitant therapies (Table 2).

In previous studies, adrenal function was monitored by assessing serum cortisol levels. In the current study, serum DHEA-S levels were analyzed and were observed to change (with a tendency to decrease) during the 8-week treatment phase in the budesonide group, with no change observed in the mesalazine group (online suppl. Table S2). The change in DHEA-S levels in the budesonide group reflects the steroid characteristics of budesonide. 
Serum cortisol levels display a large circadian variation, meaning that the timing of testing needs to be considered in order for results to be accurate and comparable; generally, cortisol levels are assessed in the morning, at the time of awakening. In contrast, circadian variation is small for DHEA-S levels, and serum DHEA-S monitoring can therefore be used as a simple index of adrenal function when assessing budesonide therapy in CD.

A previous study, conducted in several Western countries, showed budesonide $9 \mathrm{mg}$ q.d. to be more effective than mesalazine $2 \mathrm{~g}$ twice daily at inducing remission in patients with active $\mathrm{CD}$ [8]. Furthermore, a recent metaanalysis of randomized clinical trials, which included direct as well as indirect comparisons, showed that budesonide was more effective than mesalazine at inducing and maintaining remission [19]. About half of the patients in the present study were concomitantly using nutritional therapy or immunosuppressants. Use of several therapies in parallel reflects common practice in Japan, where nutritional therapy and immunomodulators are often used to support induction or maintenance therapy in patients with CD $[3,20]$. A specialized "elemental diet" as nutritional therapy has been shown to be safe for patients with CD [14], and is widely used in Japan for the treatment of mild-to-moderate $\mathrm{CD}$ in combination with ethyl cellulose-coated mesalazine $3 \mathrm{~g}$ per day. In a study that enrolled patients with $\mathrm{CD}$ who were in remission, a nutritional therapy with half of the daily calorie requirement being provided by an elemental diet was observed to be effective for maintenance of remission [14]. Furthermore, a recent meta-analysis concluded that use of enteral nutritional therapy in combination with infliximab is more effective than infliximab alone at inducing and maintaining remission in patients with $\mathrm{CD}$ [21]. In the present study, patients who were receiving $\leq 1,200 \mathrm{kcal}$ per day from nutritional therapy were eligible for inclusion. This is likely to have resulted in patients not responding to nutritional therapy being enrolled, and thus to lower efficacy values for both budesonide and mesalazine relative to those observed in preceding studies in Western populations. Another limitation of the study is the small number of patients per subgroup in the subgroup analyses. Also, most enrolled patients had used disease-related medication previously, representing a potential selection bias that could have affected the results.

In conclusion, therapy with budesonide $9 \mathrm{mg}$ q.d. was noninferior to treatment with mesalazine $1 \mathrm{~g}$ t.i.d. for remission at week 8 in patients with active mild-to-moderate CD in Japan. No safety concerns were raised with either treatment. Although the present study harbors po- tential weaknesses, such as not being statistically powered to show superiority and with a relatively small number of patients, a relatively short treatment period, concomitant drug use, and a somewhat heterogeneous patient populations in terms of disease severity, the study results demonstrate that budesonide is comparably effective to mesalazine, providing an option for therapy in Japanese patients with $\mathrm{CD}$.

\section{Acknowledgments}

This work was supported by AstraZeneca K.K., Osaka, Japan. In 2016, the rights for Entocort ${ }^{\circledR}$ in Japan were acquired by Tillotts Pharma AG, and it is now distributed in Japan by Zeria Pharmaceutical Co. Ltd. Writing support was provided by Dr. Anja Becher of Oxford PharmaGenesis, Oxford, UK, and was funded by AstraZeneca Gothenburg, Mölndal, Sweden.

\section{Statement of Ethics}

The trial was conducted in accordance with the Declaration of Helsinki International Conference on Harmonisation and Good Clinical Practice. The clinical study protocol was approved by the institutional review board. All participants provided written informed consent.

\section{Disclosure Statement}

T. Yokoyama has served as speaker and adviser for Ajinomoto Pharmaceuticals Co. Ltd., KYORIN Pharmaceutical Co. Ltd., Takeda Pharmaceutical Co. Ltd., and Zeria Pharmaceutical Co. Ltd., and as speaker for AstraZeneca, Eisai Co. Ltd., JIMRO Co. Ltd., and Mitsubishi Tanabe Pharma. S. Motoya has served as speaker, consultant, and advisory board member for Mitsubishi Tanabe Pharma and Takeda Pharmaceutical Co. Ltd., has served as speaker for Zeria Pharmaceutical Co. Ltd., and has received research funding from AbbVie GK, Yansen Pharma, and Pfizer. T. Yajima and M. Nii are employees of AstraZeneca K.K., Osaka, Japan. M. Date was an employee of AstraZeneca K.K., Osaka, Japan at the time of the study. P. Nagy was an employee of AstraZeneca R\&D Gothenburg, Mölndal, Sweden at the time of the study. Y. Suzuki has served as speaker for AbbVie GK, Mitsubishi Tanabe Pharma, and Zeria Pharmaceutical Co. Ltd. T. Hibi has served as speaker for AbbVie GK, Eisai Co. Ltd., JIMRO Co. Ltd., Mitsubishi Tanabe Pharma, and Zeria Pharmaceutical Co. Ltd., and as advisory board member for Mitsubishi Tanabe Pharma and Takeda Pharmaceutical Co. Ltd., and has received research funding from AbbVie GK, Ajinomoto Pharmaceuticals Co. Ltd., Eisai Co. Ltd., JIMRO Co. Ltd., and Zeria Pharmaceutical Co. Ltd. The other authors declare that they have no conflicts of interest. 


\section{References}

1 Asakura K, Nishiwaki Y, Inoue N, Hibi T, Watanabe M, Takebayashi T: Prevalence of ulcerative colitis and Crohn's disease in Japan. J Gastroenterol 2009;44:659-665.

2 Ministry of Health, Labour and Welfare: Report on Public Health Administration and Services 2013. http://www.mhlw.go.jp (accessed September 15, 2015).

3 Ueno F, Matsui T, Matsumoto T, Matsuoka K, Watanabe M, Hibi T: Evidence-based clinical practice guidelines for Crohn's disease, integrated with formal consensus of experts in Japan. J Gastroenterol 2013;48:31-72.

4 Dignass A, van Assche G, Lindsay JO, Lemann M, Soderholm J, Colombel JF, Danese S, D’Hoore A, Gassull M, Gomollón F, Hommes DW, Michetti P, O'Morain C, Oresland T, Windsor A, Stange EF, Travis SP; European Crohn's and Colitis Organisation (ECCO): The second European evidence-based consensus on the diagnosis and management of Crohn's disease: current management. J Crohns Colitis 2010;4:28-62.

5 Lichtenstein GR, Hanauer SB, Sandborn WJ: Management of Crohn's disease in adults. Am J Gastroenterol 2009;104:465-483.

6 Campieri M, Ferguson A, Doe W, Persson T, Nilsson LG: Oral budesonide is as effective as oral prednisolone in active Crohn's disease. The Global Budesonide Study Group. Gut 1997;41:209-214.

7 Rutgeerts P, Lofberg R, Malchow H, Lamers C, Olaison G, Jewell D, Danielsson A, Goebell $\mathrm{H}$, Thomsen OO, Lorenz-Meyer H, Hodgson $\mathrm{H}$, Persson T, Seidegard C: A comparison of budesonide with prednisolone for active Crohn's disease. N Engl J Med 1994;331:842845.

8 Thomsen OO, Cortot A, Jewell D, Wright JP, Winter T, Veloso FT, Vatn M, Persson T, Pettersson E: A comparison of budesonide and mesalamine for active Crohn's disease. International Budesonide-Mesalamine Study Group. N Engl J Med 1998;339:370-374.

9 Suzuki Y, Motoya S, Takazoe M, Kosaka T, Date M, Nii M, Hibi T: Efficacy and tolerability of oral budesonide in Japanese patients with active Crohn's disease: a multicentre, double-blind, randomized, parallel-group phase II study. J Crohns Colitis 2013;7:239247.

10 Greenberg GR, Feagan BG, Martin F, Sutherland LR, Thomson AB, Williams CN, Nilsson LG, Persson T: Oral budesonide for active Crohn's disease. Canadian Inflammatory Bowel Disease Study Group. N Engl J Med 1994;331:836-841.

11 Guyatt G, Mitchell A, Irvine EJ, Singer J, Williams N, Goodacre R, Tompkins C: A new measure of health status for clinical trials in inflammatory bowel disease. Gastroenterology 1989;96:804-810.

12 Hashimoto H, Green J, Iwao Y, Sakurai T, Hibi T, Fukuhara S: Reliability, validity, and responsiveness of the Japanese version of the Inflammatory Bowel Disease Questionnaire. J Gastroenterol 2003;38:1138-1143.

13 Best WR, Becktel JM, Singleton JW, Kern F Jr: Development of a Crohn's disease activity index. National Cooperative Crohn's Disease Study. Gastroenterology 1976;70:439-444.

14 Takagi S, Utsunomiya K, Kuriyama S, Yokoyama $\mathrm{H}$, Takahashi S, Iwabuchi M, Takahashi H, Takahashi S, Kinouchi Y, Hiwatashi N, Funayama Y, Sasaki I, Tsuji I, Shimosegawa T: Effectiveness of an "half elemental diet" as maintenance therapy for Crohn's disease: a randomized-controlled trial. Aliment Pharmacol Ther 2006;24:1333-1340.

15 Tromm A, Bunganic I, Tomsova E, Tulassay Z, Lukas M, Kykal J, Bátovský M, Fixa B, Gabalec L, Safadi R, Kramm HJ, Altorjay I, Löhr
H, Koutroubakis I, Bar-Meir S, Stimac D, Schäffeler E, Glasmacher C, Dilger K, Mohrbacher R, Greinwald R; International Budenofalk Study Group: Budesonide $9 \mathrm{mg}$ is at least as effective as mesalamine $4.5 \mathrm{~g}$ in patients with mildly to moderately active Crohn's disease. Gastroenterology 2011;140: 425-434.

16 Newcombe RG: Interval estimation for the difference between independent proportions: comparison of eleven methods. Stat Med 1998;17:873-890.

17 Newcombe RG: Two-sided confidence intervals for the single proportion: comparison of seven methods. Stat Med 1998;17:857-872.

18 McKeage K, Goa KL: Budesonide (Entocort EC Capsules): a review of its therapeutic use in the management of active Crohn's disease in adults. Drugs 2002;62:2263-2282.

19 Moja L, Danese S, Fiorino G, Del Giovane C, Bonovas S: Systematic review with network meta-analysis: comparative efficacy and safety of budesonide and mesalazine (mesalamine) for Crohn's disease. Aliment Pharmacol Ther 2015;41:1055-1065.

20 Hida N, Nakamura S, Hahm KB, Sollano JD, Zhu Q, Rani AA, Syam AF, Kachintorn U, Ueno F, Joh T, Naito Y, Suzuki H, Takahashi S, Fukudo S, Fujiwara Y, Kinoshita Y, Uchiyama K, Yamaguchi Y, Yoshida A, Arakawa T, Matsumoto T; IGICS Study Group: A questionnaire-based survey on the diagnosis and management of inflammatory bowel disease in East Asian countries in 2012. Digestion 2014;89:88-103.

21 Nguyen DL, Palmer LB, Nguyen ET, McClave SA, Martindale RG, Bechtold ML: Specialized enteral nutrition therapy in Crohn's disease patients on maintenance infliximab therapy: a meta-analysis. Therap Adv Gastroenterol 2015;8:168-175. 